\title{
Algunas reflexiones sobre la Sexualidad y el Trauma ${ }^{1}$
}

\author{
Rodrigo Rojas Jerez $z^{2}$ \\ Santiago, Chile
}

Dentro de la metapsicología psicoanalítica, las teorías sobre la sexualidad infantil, de la fantasía inconsciente y por otro lado la teoría del trauma, parecieran haber estado en pugna desde un comienzo en la historia del psicoanálisis. En el presente trabajo pretendo realizar una lectura de la cuestión partiendo desde Freud - Ferenczi pasando por Winnicott, en la que busco destacar las raíces de Winnicott en el pensamiento de Ferenczi. A modo de integración se propongo destacar una lectura diversa del Complejo de Edipo, incluyendo los elementos traumáticos presentes en el mito y que se encuentran en la base de la expresión de la sexualidad del protagonista.

Palabras clave: Sexualidad, Trauma, Winnicott, Ferenczi, Freud

Within psychoanalytic metapsychology, theories of infantile sexuality, of unconscious fantasy and, on the other hand, the theory of trauma, seem to have been in conflict from the beginning in the history of psychoanalysis. In the present work I intend to make a reading of the question starting from Freud - Ferenczi through Winnicott, in which I seek to highlight the roots of Winnicott in Ferenczi's thought. By way of integration, I propose to highlight a diverse reading of the Oedipus Complex, including the traumatic elements present in the myth and that are at the base of the expression of the protagonist's sexuality.

Key Words: Sexuality, Trauma, Winnicott, Ferenczi, Freud English Title: Some reflections on Sexuality and Trauma

\section{Cita bibliográfica / Reference citation:}

Rojas Jerez, R. (2021). Algunas reflexiones sobre la Sexualidad y el Trauma. Clínica e Investigación Relacional, 15 (2): 442-448. [ISSN 1988-2939] [Recuperado de www.ceir.info ] DOI:

$10.21110 / 19882939.2021 .150210$

\footnotetext{
${ }^{1}$ Trabajo leído en las VI Jornadas de Psicoanálisis Relacional, que sobre el lema: "Winnicott en el Psicoanálisis Relacional Actual: Creatividad, intersubjetividad y el jugar en la clínica" se realizaron online desde Barcelona, los días 14 y 15 de Mayo 2021, organizadas por el Instituto de Psicoterapia Relacional y el Institut Català D. Winnicott

${ }^{2}$ Ps. Rodrigo Rojas Jerez, Psicoanalista, Miembro y Profesor Titular Asociación Psicoanalítica de Santiago (APSAN-IPA). Miembro y Profesor Titular Asociación Psicoanalítica Chilena (APCH-IPA). Miembro Board Encuentros Latinoamericano sobre el pensamiento de Winnicott. Coordinador Comité Traducción de las Obras Completas de D. Winnicott.
} 
Sexualidad y trauma en el psicoanálisis han estado aparentemente interrelacionadas ya desde un comienzo, pero al mismo tiempo Freud tempranamente descartó en su carta a Fliess la relación entre histeria y trauma al señalar "ya no le creo a mis histéricas" haciendo alusión a la etiología de la fantasía inconsciente de la histeria descartando el origen traumático de la misma, sepultando la investigación de lo traumático como un hecho real y psíquico dentro del psicoanálisis, reservándole sólo un espacio teórico.

Los primeros intentos de continuar dicha investigación fueron de Sandor Ferenczi quién a fines de la década de los '20 y de comienzo de los '3o en su artículo "Análisis de niños con Adultos" (1928) realiza una detallada descripción del desarrollo en la transferencia de lo que él llamó "traumatogénesis" como un proceso donde el sujeto expuesto al trauma en un primer momento queda sometido a una parálisis del yo resultado de la imposición y dominio por parte del agresor. Se desarrolla así ante nosotros lo que el autor llama a ansiedad frente a la agonía psíquica y física impensable, hasta aquí como Diaz (2003) destaca lo que Ferenczi llamó conmoción psíquica, un hecho violento pero que no genera patología; en otras palabras, no todo hecho que vaya más allá de nuestra capacidad de ligar necesariamente deviene patógeno. Un segundo momento central en la descripción del autor es la mentira o desmentida, es decir la afirmación del entorno de que no ha pasado nada -frente a las manifestaciones de ansiedad de aniquilamiento-, es decir ya no es sólo la conmoción traumática la que es rechazada sino que la expresión emocional de las consecuencias en la vida psíquica del infante las que son desmentidas por el entorno, y junto con ellas la posibilidad de experienciar del niño. Ferenczi dirá "la mentira del entorno humano se instala en el psiquismo frágil del infante". La desmentida de los adultos se constituye en un elemento central de la patología para Ferenczi. Nos encontramos frente al dominio del conflicto entre el yo y el mundo del cual se depende.

Posteriormente en su importante artículo "Confusión de lengua entre los adultos y el niño" (1931), constata la reproducción del trauma en la situación analítica pero además la posibilidad de la re-traumatización dentro de la misma escena en la que esta vez el analista se resiste de sostener la realidad de las ansiedades de aniquilamiento de nuestro paciente. Así el analista mantendría uns relación defensiva con la misma. El autor destacó así las resistencias del analista para analizar el trauma. Agrega además que esto no significa negar la dimensión sexual de la vida psíquica de los niños, pero que si requiere de una nueva investigación, es decir él va a plantear que los juegos infantiles tienen un raigambre erótico pero que (siguiendo con precisión a Freud de los Tres Ensayos, en referencia a las teorías sexuales infantiles) aún permanecen en el nivel de ternura, es decir no esperando la respuesta de los deseos genitales de los adultos, esto es lo que el autor llamó "Confusión de Lenguas", destacando que el acceso a la genitalidad señala un cambio estructural en el 
desarrollo y por lo tanto en la responsabilidad, "las perversiones no son infantiles más que si permanecen a nivel de la ternura; cuando se cargan de pasión y de culpabilidad inconsciente testimonian posiblemente una estimulación exógena" (Ferenczi, 1932, pag 148). Derivado de esto Ferenczi va a definir y desarrollar los conceptos de identificación con el agresor (atribuida a Anna Freud), ecuación simbólica (atribuida a Hanna Segal), introyección ansiosa del culpa del agresor, ansiedad de muerte o aniquilamiento, progresión traumática (o pseudo madurez), escisión de la personalidad de manera de desmentir el trauma y de auto-sostenerse generando una adaptación autoplástica que asegura la continuidad de la relación de dependencia con el mundo adulto relevante afectivamente.

A pesar (o quizás por lo mismo) de estos importantes aportes a la investigación de la realidad, de las condiciones de patología del trauma y de la necesidad de reformular la teoría de la sexualidad en la patogénesis, gran parte de la obra de Ferenczi permaneció sepultada hasta la mitad de la década de los '80, tras su temprana muerte en los años '30. Sin embargo, fue Winnicott el que en la escuela inglesa comienza a partir de lo que yo llamo la definición metapsicológica de la dependencia del infante como estructurante y estructural, es que revisita la realidad de lo traumático y sus consecuencias en lo psíquico y no menos relevante en la metapsicología. A la luz de esto Winnicott (1965) en "El concepto de trauma en relación con el desarrollo del individuo dentro de la familia" va a señalar que "intentará relacionar la función de la familia con la idea de trauma, lo cual implica estudiar el trauma como concepto de la metapsicología. El nexo entre ambas ideas es que la familia brinda al niño en crecimiento una protección contra el trauma."(pag 161). Es decir, el autor va a señalar que "el trauma es una falla relativa a la dependencia." (pag 178) y al quiebre de la protección de la familia. Es decir, frente a una relación de dependencia que en la que el bebé ha logrado sentirse en brazos de una madre confiable y que ha mantenido las condiciones para que las necesidades de la continuidad de su existencia física y psíquica, ocurre un hecho que termina con dicho sostén. Winnicott dice "Trauma significa el quiebre de la continuidad de la línea existencia individual. Es sólo en la continuidad de existencia es que el sentido del self, de sentirse real, y de ser, puede eventualmente establecerse como un hecho de la personalidad individual." (Winnicott, D., 1967, pag 22.).

Así el quiebre de la continuidad de la existencia es vivida por el bebé como ansiedades de aniquilamiento (caída infinita, despersonalización, fragmentación, pérdida de la orientación espaciotemporal), impensables, que avasallan al yo en las posibilidades del mismo. Pero la emergencia de dichas ansiedades puede eventualmente permitir el desarrollo del yo si es que la madre o el entorno se encuentra solícito a sostener dichas ansiedades, es decir lo traumático no deviene en patología. Pero hay una posibilidad y es 
que el entorno no esté disponible para dicho sostén en este momento el yo se ve, al igual que lo plantea Ferenczi, obligado a "reaccionar" y escindirse, retirando su relación de dependencia del objeto real, para establecer una relación con un objeto narcisista interno u externo que busca proteger de la repetición de la injuria y el quiebre de la continuidad de la existencia. La reacción en la vida del sujeto sustituye a la acción, la sobrevivencia (y el orgullo propio de la misma) domina la escena, manteniéndose desconocida la vivencia y la relación con la vitalidad. Es como si la vida emocional de sujeto se mantuviera escindida donde se establece una relación concreta con los objetos que se mantiene alejada del otro tipo de relación que se mantiene replegada de la realidad y que Winnicott llama relación con objetos subjetivos (a nivel del fantaseo, de la fabulación, del delirio, de la alucinación, etc.)

De ahí que predominen en la observación de Winnicott los fenómenos esquizoides en la vida de la investidura de los sujetos. El replegamiento pasa a ser un fenómeno clínico de alto interés metapsicológico. La sexualidad como un aspecto de la investidura queda destinada a seguir el destino de toda investidura, es decir carente de la experiencia de realidad, fragmentada y fragmentaria. Pero para Winnicott, las cosas son más complejas, porque en el desarrollo del yo las fuentes de su integración son dos, por un lado, el sostén que la madre entrega y que otorga las condiciones de necesidad para la emergencia de un yo de acuerdo al "potencial heredado" del individuo. Por el otro lado es la viviencia de la pulsión, esto dado que justamente (muy apegado a Freud) la pulsión tendría objeto y meta esta se alcanzan en la medida que el yo se organiza (desde las condiciones dadas por el sostén) en pos de dicha meta y objeto. En condiciones de precariedad del yo, dichas exigencias pueden constituirse en un avasallamiento intolerable por un lado, pero por otro lado este es el camino también en que la sexualidad es tomada a modo de "terapia", es decir inconscientemente se utiliza la sexualidad y la excitación como fuente de integración forzada, pero que se encuentra dominada por el interés del yo por su propia y frágil integridad. No habría un interés edípico en la sexualidad sino de sostener la unidad del self. Así podemos presenciar por ejemplo la fetichización del objeto transicional, el que deja de ser un símbolo de la relación con la madre para pasar a ser la "cosa en sí".

En este punto Winnicott rescata permanentemente la diferencia que la palabra trauma trae en el crecimiento del sujeto, como vimos para el autor el trauma es relativo a la dependencia y por lo tanto diversa en la psicogenia. En un caso de una chica de 12 años que está por diversas condiciones expuesta a un exhibicionista, en el momento que Winnicott trabajaba con ella. Lo traumático pareciera radicar en que la paciente está elaborando el ingreso en la genitalidad del estadio puberal con la integración de la ambivalencia. Es en ese minuto es expuesta -en una hospitalización quirúrgica de largo 
aliento- a la conmoción, minuto en que despliega todas las defensas y manifestaciones largas de detallar, pero que hablan como el autor señala como "la destrucción de la pureza de la experiencia individual". Esto es que en un momento en que la investidura y su devenir en la ligadura se los sistemas como diría Freud, es en este punto donde la estructura de la niña se ve sometida al avasallamiento no sólo de la pulsión, sino de la violencia de la interrupción del ritmo, del tiempo, de la propia maduración del yo.

Freud, S. Al revisar el problema económico del sueño y repetición el trauma define el "principio de inexcitabilidad de los sistemas no investidos". (1917d, 1920g). Al respecto señala "un sistema de elevada investidura en sí mismo es capaz de recibir nuevos aportes de energía fluyente y transmudarlos en investidura quiescente, vale decir, <<ligarlos>> psíquicamente. Cuanto más alta sea la energía quiescente propia, tanto mayor será también su fuerza ligadora; y a la inversa: cuanto más baja su investidura, tanto menos capacitado estará el sistema para recibir energía afluyente y más violentas serán las consecuencias de una perforación de la protección antiestímulo" (Freud, S.1920g, pag. 30).

Reflexionemos a partir del aporte de Kohut a la lectura del Edipo que entrega una mirada relacionada con el trauma y que está inscrito en el propio nombre de Edipo, es decir pies hinchados. Como sabemos el origen de los pies hinchados está en el intento de filicidio de Layo y Yocasta (recordar que Edipo fue amarrado de los pies al nacer para ser librado a su muerte en el campo) que luego es rescatado por un campesino que lo entrega a sus padres adoptivos. Kohut nos llama la atención sobre este punto, pero creo que sólo considerar el trauma en el desarrollo de la sexualidad y de lo que Winnicott llama el individuo sano, tiene el riesgo de sólo victimizar Edipo.

Pienso que al igual que como en la historia del psicoanálisis se ha tratado de negar el trauma en Edipo; veo en la misma medida que la escisión entre los padres naturales y los adoptivos de Edipo tiene el resultado propio de la tragedia, la negación tanto del trauma, como la victimización de Edipo sin duda nos llevará nuevamente a la tragedia. La integración de lo traumático en la historia de la sexualidad en Edipo es esencial en la mirada que podemos tener en la lectura de nuestra clínica desde este modelo. Es decir, la estructuración del sujeto está dada de acuerdo a Winnicott por el rostro de la madre que mira, que nombra, pero dicha inscripción no cae en la pasividad del que es concebido, sino que cae en el mundo infinitamente personal del bebé. Si la curiosidad de Edipo no se hubiese encontrado con su propia negación y la negación de sus padres adoptivos, quizás hubiera reconocido en el oráculo no sólo su origen traumático, sino que lo hubiese podido integrar, sin tener que huir del mismo, es en la huida donde el origen traumático deviene en la tragedia de Edipo y podríamos decir del núcleo de la sexualidad en la patología. 
Es verdad que el oráculo le señala que él es el potencial asesino de su padre, él no duda en un huir ya que no desea asesinar a su padre dando por hecho a fuego la realidad que se le ha presentado sin dudar, no del oráculo sino de lo conocido por él como hechos. Bastaba acercarse a su padre adoptivo para enterarse de la realidad, él no mataría a su amado padre ya que él no lo era. Pero al parecer es difícil pensar que uno no es un príncipe.

Edipo huye, pero no huye como un simple hombre huyendo/buscando su destino, sino que huye como príncipe. Si bien él en su huida buscaba no asesinar a su padre, no huyó de la idea de asesinar. Sabemos que Edipo asesina a Layo en el cruce de los caminos. Layo, no va como padre, va como dignatario. Edipo se enfrenta a Layo por el derecho a paso, por el derecho de mayor valía de su estandarte, en la disputa asesina. No deja de ser curioso que Edipo se interne por el mismo camino que trae a Layo frente a sí, ¿qué busca Edipo? Ser condenado, ser nombrado Rey, conquistar nuevos territorios para su padre adoptivo. Sabemos que se encuentra con la Esfinge, y que resuelve su pregunta y libera al pueblo de Tebas, entonces sabemos que Edipo es un hombre inteligente, que piensa, pero que curiosamente ha evitado pensar, sobre su realidad y sobre su historia. Ingresa a Tebas, el pueblo liberado de la maldición lo nombra Rey, sabe de un pueblo sin Rey luego de haber asesinado a un Rey en el cruce de caminos. ¡Bien! Logra ser tratado como héroe pero que no logra pensar quién es él. Si, porque finalmente nombrado Rey él acepta como mujer (Reina) a Yocasta, viuda, probablemente deprimida (maldición, encierro, muerte de su marido, etc) una mujer que claramente tiene la edad para ser su madre, y él nuevamente se somete a los designios casándose para ser Rey. Había un pueblo entero, donde él podría haberse enamorado de otra mujer, quizás más joven, quizás más vitalizada, en edad de ser madre de sus hijo/as. Edipo opta por el poder de no existir como sujeto. La amenaza de la que huye, la verdad, de haber sido objeto de un intento de filicidio lo lleva claramente al asesinato y al poder. Edipo no se enamora de su madre, él se enamora del poder conquistado al mantener la desmentida de su realidad traumática.

La huida de Edipo lo muestra frágil frente a la propia responsabilidad, huye de la afirmación del oráculo de que es potencialmente un parricida. Él está dispuesto definirse a través del rostro del oráculo, se identifica a los dichos del oráculo.

\section{REFERENCIAS}

Ferenczi, S. (1931): "Análisis de niños con Adultos" En OC Tomo IV, Ed Espasa-Calpe, España.

Ferenczi, S. (1932): "Confusión de lenguas entre los adultos y el niño" En OC Tomo IV, Ed EspasaCalpe, España. 
Freud, S. (1917d): "Complemento metapsicológico de los sueños", OC Vol14, Amorrortu Editores, Buenos Aires.

Freud, S. (1920g): "Más allá del principio del placer", OC Vol 18, Amorrortu Editores, Buenos Aires.

Winnicott, D. (1965): "El concepto de trauma en relación con el desarrollo del individuo dentro de la familia", En "Exploraciones psicoanalíticas I" Editorial : Paidos, Buenos Aires.

Winnicott, D. (1967): "El Concepto de individuo sano" En "El Hogar, Nuestro Punto de Partida", Editorial Paidos, Buenos Aires.

Winnicot, D. (1967): "El papel del espejo de la madre y la familia en el desarrollo del niño" En: "Realidad y Juego" Ed. Gedisa, Barcelona.

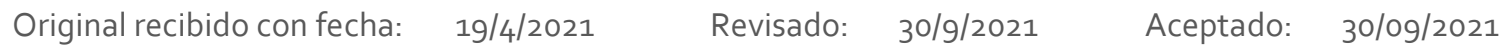

